Pablo Guadarrama González. Profesor de Mérito de la Universidad Central de Las Villas, Santa Clara, Cuba. Académico titular de la Academia de Ciencias de Cuba. Doctor en Ciencias (Cuba), doctor en Filosofía (Leipzig). Profesor de la Maestría en Ciencia Política de la Universidad Católica de Colombia-Universidad de Salerno. Línea de investigación: Filosofía política latinoamericana. Libros: Pensamiento filosófico latinoamericano. Humanismo, método e historia. Universitá degli Studi di Salerno-Universidad Católica de Colombia-Planeta, Bogotá. Tomo I, II y III.

Contacto: pabloguadarramag@gmail.com 


\section{POSIBILIDADES Y OBSTÁCULOS \\ DE LA DEMOCRACIA Y LOS \\ DERECHOS HUMANOS EN LA \\ FILOSOFÍA POLÍTICA DE AMÉRICA \\ LATINA}

Pablo Guadarrama González

Universidad Católica de Colombia

POSSIBILITIES AND OBSTACLES OF DEMOCRACY AND HUMAN RIGHTS

WITHIN POLITICAL PHILOSOPHY

\section{FROM LATIN AMERICA}

DOI: $1017450 / 160110$

Fecha de recepción 10 de septiembre de 2015; fecha de aceptación 11 de noviembre de 2015. El presente artículo se ha realizado en el marco del proyecto de investigación desarrollado en la Universidad Central de Las Villas, Santa Clara, Cuba. 


\section{Resumen}

Como parte de la filosofía política a escala universal en América Latina, han germinado ideas y propuestas enriquecedoras que contribuyen a esclarecer la problemática de las posibilidades y obstáculos para el desarrollo de la democracia y los derechos humanos. No obstante el reconocimiento de la existencia de innumerables obstáculos para la realización más elaborada y de mayores conquistas democráticas y de los derechos humanos, prevalece una concepción progresiva del desarrollo social, auspiciada por el fortalecimiento de la lucha por tales derechos.

\section{Palabras clave}

Filosofía política, humanismo, democracia y derechos humanos

\section{Abstract}

As part of political philosophy at the universal level in Latin America have germinated ideas and enriching proposals that contribute to clarify the possibilities and obstacles for the development of democracy and human rights problems. Despite the recognition of the existence of countless more elaborate obstacles and greater democratic achievements and human rights prevails a progressive concept of social development, sponsored by the strengthening of the fight for such rights.

\section{Keywords}

Political philosophy, humanism, democracy and human rights

Si bien la democracia y los derechos humanos deben ser considerados, ante todo, como productos culturales, en todas sus dimensiones sociopolíticas y jurídicas institucionalizadas, y en especial valorados como conquistas del proceso civilizatorio universal -que en modo alguno debe reducirse a la cultura occidental, independientemente del mayor protagonismo que ella haya podido haber desempeñado en dicho proceso ${ }^{1}-$, lo cierto es que en la conformación de constituciones, legislaciones, códigos, etcétera, ha

1. Véase: P. Guadarrama, “Democracia y derechos humanos: ¿Conquistas’ exclusivas de la cultura occidental?”, en Nova et Vetera, Escuela Superior de Administración Pública, Bogotá, II Semestre 2009, pp. 79-96; http://es.scribd.com/ doc/73843874/Revista-Espacio-Critico-n\%C2\%BA-13-julio-diciembre-2010\#outer_page_3. 
tenido un papel protagónico la filosofía política que en cada época y contexto se haya elaborado. En tal sentido, el ámbito latinoamericano ha constituido también un caldo de cultivo favorable en el que han germinado ideas y propuestas desde y para la filosofía política universal enriquecedoras de tales conquistas, que ayudan a esclarecer la problemática de las posibilidades y obstáculos para el desarrollo de la democracia y los derechos humanos.

Algunos de los principales rasgos que han caracterizado la perspectiva humanista de la filosofía política latinoamericana, en particular en relación con la democracia y los derechos humanos ${ }^{2}$, en su articulación con el pensamiento universal se han destacado por sus elementos aportantes en la comprensión de las diferentes demandas de humanismo práctico ${ }^{3}$ sobre el tema en cuestión. No cabe duda de que tanto en la historia económica, política, social, jurídica y cultural de la humanidad como especialmente en su pensamiento filosófico y político, en particular en el ámbito latinoamericano y caribeño, se ha evidenciado un significativo progreso de la tradición humanista práctica -que debe diferenciarse debidamente del filantrópico humanismo abstracto o del simple cultivo de las humanidades- en relación con el desarrollo de la democracia y los derechos humanos.

Nadie debe ignorar o subestimar los significativos aportes de los pueblos y pensadores europeos, solo a partir del despliegue de la modernidad, al desarrollo de las concepciones y prácticas democráticas y de los derechos humanos. Pero, ¿qué razones hay para ignorar o subestimar las contribuciones en tales temas de los pueblos y pensadores latinoamericanos en las distintas etapas de su evolución histórica? ¿Acaso la cultura occidental se conformó desde la Antigüedad unilateralmente solo exportando a otros pueblos ideas e instituciones, sin apropiarse de valiosos elementos en todos los planos de otras culturas ancestrales anteriores o al margen de ella ${ }^{4}$ ?

Es reconocido que la cultura grecolatina supo muy sabiamente nutrirse de ancestrales expresiones culturales, no solo de las más cercanas, como las Medio Oriente o el norte de África, sino también del Lejano Oriente, como se puso de manifiesto en toda

\footnotetext{
2. Véase P. Guadarrama, "El humanismo como pilar de los derechos humanos y la democracia”, en Filosofía y teoría política, Memorias del IV Congreso Internacional de Filosofía del Derecho, Ética y Filosofía Política, Universidad Libre, Bogotá, 2014, pp. 227-270.

3. Por humanismo práctico -término utilizado por Marx en sus trabajos tempranos como La sagrada familia y los Manuscritos económicos y filosóficos de 1844, así como los de humanismo concreto, humanismo positivo y humanismo culto, que diferenciaba del humanismo real de Feuerbach- puede entenderse una postura de compromiso activo, militante y arriesgado con la defensa de la dignidad de determinados grupos humanos, que se diferencia del humanismo abstracto, el cual se limita a simples declaraciones filantrópicas.

4. Véase P. Guadarrama, "Democracia y los derechos humanos en los pueblos originarios de América”, en Cuadernos Americanos, UNAM, 2014, 149, pp. 135-147.
} 
la información que Alejandro Magno le trajo a Aristóteles desde la India y Persia. Nadie medianamente informado ignora que la formación de Tales de Mileto se desarrolló en Egipto. En verdad, lo que se ha producido desde los albores de la civilización es un proceso de transculturación universal mediante el cual unos pueblos, para bien o para mal, han aprendido unos de otros, y así han ido construyendo valores comúnmente compartidos para mejorar su calidad de vida, como es el caso de la cultura democrática y de los derechos humanos.

¿Qué posibles consecuencias puede traer para la formación de las actuales y futuras generaciones intelectuales latinoamericanas el hecho de que prevalezca el criterio de que solo autores europeos o norteamericanos han sido los exclusivos cultivadores de ideas originales y valiosas sobre los derechos humanos y las diversas formas de democracia? Un desprejuiciado análisis de esta pregunta, que supere cualquier tipo de eurocentrismo u otro etnocentrismo, puede resultar muy pertinente si permite de algún modo, sin subestimar las contribuciones de pueblos y pensadores de distintas latitudes, revelar, destacar y valorar las de los pueblos y pensadores latinoamericanos de diversas épocas como la Ilustración ${ }^{5}$. Un estudio de esta naturaleza puede estimular la confianza epistemológica e ideológica en las actuales y futuras generaciones intelectuales para generar nuevos conceptos, teorías, reflexiones políticas, jurídicas, filosóficas, etcétera, sobre cómo orientar mejor la vida democrática de los pueblos de esta región y a la vez proponerlas para otras latitudes del cada vez más globalizado mundo contemporáneo.

Cada vez en mayor proporción los intelectuales latinoamericanos, desde diversas perspectivas, le han dedicado atención al tema de la democracia y los derechos humanos, y siempre de un modo u otro han debido transitar por el terreno de la filosofía política. Como asegura Norbert Lechner:
La democracia se había convertido en el tema central de las ciencias sociales sura- mericanas. La radical alteración de la vida cotidiana que se da como consecuencia del golpe de Estado y la pérdida de seguridad y consecuente incertidumbre lleva a los intelectuales a una revalorización de la democracia formal a partir de su propia experiencia particular. ${ }^{6}$

\footnotetext{
5. Véase P. Guadarrama, "Derechos humanos y democracia en el pensamiento ilustrado latinoamericano", en Latinoamérica, Revista de Estudios Latinoamericanos, Centro de Investigaciones sobre América Latina y el Caribe (CIALC), Universidad Nacional Autónoma de México, México, D. F., 1, 2015, pp. 235-275.

6. N. Lechner, "De la revolución a la democracia. El debate intelectual en América del Sur", en Opciones, 6, mayo-agosto 1985 , p. 57.
} 
La preocupación humanista ha estado muy presente en los cultivadores de la filosofía política latinoamericana ${ }^{7}$. Al respecto Alejandro Serrano Caldera, considera que:

Es innegable la necesidad de proteger al ser humano en su individualidad contra los abusos del Estado y del poder, y de mejorar los mecanismos jurídicos, nacionales e internacionales. El ser humano, como tal, tiene derecho a la vida, a la integridad, a la dignidad y a la libertad, cualquiera que sea su condición socioeconómica, política o ideológica y cualquiera el país en que se encuentre. Este es un principio universal y genérico. En ese espíritu estoy consciente de la necesidad insoslayable de proteger al ser humano en su debilidad frente al poder y sus abusos, y frente a la perversión demagógica que pretende justificar la agresión contra el individuo, en nombre de la razón de Estado, defensa de colectividad, de la Humanidad con mayúscula y del futuro, como si fuera posible construir la esperanza, la libertad y la justicia sobre los despojos de la persona humana. ${ }^{8}$

La preocupación principal del pensamiento humanista latinoamericano se ha centrado en el respeto a la dignidad humana y el reconocimiento de los valores y derechos de hombres y mujeres, minorías étnicas y sectores marginales.

El hecho de que diccionarios y otras publicaciones recojan innumerables definiciones de los conceptos de derechos humanos, Estado, democracia, entre otros, constituye una expresión de que hombres de distintas latitudes y épocas, entre ellos los latinoamericanos, han reflexionado sobre ellos, tomando en consideración como presupuesto la diversidad de criterios -incluso abiertamente contradictorios- existentes al respecto. Pero, este hecho no debe en modo alguno limitar la formulación de nuevas definiciones y problemas sobre sus particularidades y nexos.

Resulta preocupante la idea de Humberto Maturana, quien no recomienda argumentar la necesidad de la democracia y, por tanto, no defenderla: "Depende de lo que queramos, pero si uno se descorazona, no hace nada. Una democracia es una obra de arte que se crea cotidianamente. No se puede defender, solamente se puede vivir; en el momento en que usted la defienda genera una tiranía". Ser consecuente con esta postura significaría no solo abandonar la producción teórica sobre la democracia, sino algo peor: dejarse arrastrar por la existencial vivencia cotidiana del arte de la democracia, sin

7. Véase P. Guadarrama, “Derechos humanos desde la filosofía política latinoamericana”, en Derecho y realidad, Facultad de Derecho y Ciencias Sociales. Universidad Pedagógica y Tecnológica de Colombia, 22, II Semestre 2013, Tunja, pp. 133-154. 8. A. Serrano Caldera, Los dilemas de la democracia, UAM, México, 1995, p. 69.

9. H. Maturana, La democracia es una obra de arte. Mesa Redonda Magisterio, Bogotá, 1995, p. 82. 
saber a qué lugar esta actitud puede conducir, con muchas posibilidades de que lleve a regímenes de profundidad dictatorial.

Por supuesto que todo dependerá, en buena medida, de lo que se entienda por derechos humanos y democracia, como lo demanda el marco conceptual de una investigación de mayor perspectiva sobre la perspectiva humanista de la filosofía política latinoamericana sobre la democracia y los derechos humanos ${ }^{10}$. Pero aun así, habrá que tomar conciencia de que cualquier clasificación conceptual de especificidades filosóficas y subordinación jerárquica entre ellas -por justificada que sea desde la perspectiva docente o investigativa al delimitar sus objetos respectivos de estudio-, de algún modo atentará siempre contra el carácter integrador y de concepción teórica generalizadora y racional del mundo que el hombre le ha reservado a la actividad filosófica desde su gestación y al análisis científico, en especial a partir de la modernidad.

En la aproximación a los conflictivos y polisémicos significados de los conceptos de derechos humanos y democracia, desempeñan un papel significativo los puntos de referencia, perspectivas epistemológicas y objetivos del investigador en cuestión, pero también su postura ideológica. Sabido es el arraigo que ha tenido en América Latina, en particular desde las últimas décadas del siglo XX -con el debilitamiento gradual de los anteriormente predominantes regímenes totalitarios-, el estudio de tales problemáticas sobre los derechos humanos y la democracia.

Resulta bien conocido que las dictaduras militares latinoamericanas trasladaron las conflictivas situaciones de crisis económicas a los gobiernos democráticos que les sucedieron, pues "Las transiciones de los últimos años se dan en condiciones de crisis económica, los regímenes militares no fueron capaces de solucionar ni la crisis de la deuda, ni la crisis de la acumulación". ${ }^{11}$

El carácter polisémico de los conceptos de derechos humanos y de democracia obliga, siempre que se analicen con detenimiento, a establecer algunos parámetros semánticos que contribuyan al manejo posterior de sus derivaciones y empleos. Estos temas encierran profundas controversias ideológicas, las cuales no es posible desatender a la hora de enjuiciar el asunto, bien para asumirlas o bien para criticarlas. En verdad, "Nunca como en el presente parecen haber gozado los derechos humanos de un grado de reconocimiento jurídico comparable a la escala planetaria. Y semejante reconocimiento convierte esos derechos - por encima o por debajo de sus nada infrecuentes violaciones,

10. Véase P. Guadarrama, "La perspectiva humanista de la filosofía política latinoamericana sobre la democracia y los derechos humanos", Informe de proyecto de investigación de la Universidad Católica de Colombia presentado al IV Seminario Internacional de Intercambio Académico, Mendoza, Argentina, 3 y 4 de septiembre de 2015.

11. P. H. Smith, "Crisis y democracia en América Latina”, en Desarrollo Económico: Revista de Ciencias Sociales, 31, 123, octubre-diciembre 1992, p. 375. 
allí donde alcanzan a regir, y de su generalizada falta de aplicación, allí donde solo rigen nominalmente- algo así como en un hecho incontrovertible". ${ }^{12}$

Se requiere analizar, en principio, algunos de los fundamentos conceptuales del Estado para poder enjuiciar como se debe la interacción entre derechos humanos y democracia. Resulta imprescindible poseer una visión general de los fundamentales ejes teóricos y un adecuado manejo de los principales elementos caracterizadores en los cuales se centra la interrelación entre estos dos conceptos para poder proceder a un análisis más efectivo de casos concretos.

Solamente un conocimiento preciso sobre el origen, desarrollo, naturaleza y principales expresiones de los conceptos de derechos humanos y democracia, permite facilitar las debidas inferencias lógicas de su mejor interconexión. Pero, en principio, es preciso valorar en alto grado la significación que tiene el derecho en general para la conformación del humanismo práctico, en tanto que:

El derecho tiene, pues, un enorme peso en la configuración de la vida humana social. Cuanto más avanzadas son las sociedades, menos espacio hay para la acción espontánea y natural de los individuos y hay más para la acción pautada y orientada por las normas jurídicas. Un ordenamiento jurídico será más justo en la medida que establezca pautas de conducta (comportamiento) que favorezcan la realización de aquellos valores adecuados al momento histórico y cultural de una sociedad concreta y a los intereses objetivos de las mayorías. ${ }^{13}$

Una reflexión profunda sobre algunas de las principales posturas filosóficas desarrolladas en la historia de la humanidad, en especial en la modernidad, sobre temas de contenido antropológico, ético, político y jurídico hace posible analizar debidamente no solo el derecho en general, sino en particular la conformación y defensa de los derechos humanos en su interacción con la democracia y, sobre todo, sus posibilidades y obstáculos.

Constituye una necesidad insoslayable que los funcionarios públicos de diversas instancias y niveles conozcan con profundidad los fundamentos teóricos y conceptuales sobre la especificidad de los términos comúnmente conocidos como valores éticos, condición humana, derechos humanos y democracia ${ }^{14}$. Pero más allá del conocimiento teórico de estos, se debe lograr que desarrollen competencias y habilidades para operar

12. J. Muguerza, Fundamentación de los derechos humanos, Editorial Debate, Madrid, 2006, p. 153.

13. H. Samour, Filosofia del derecho, UCA Editores, San Salvador, 2001, p. 33.

14. Véase P. Guadarrama, "Condición humana, valores éticos, derechos humanos y democracia: la filosofía política latinoamericana”, Cultura latinoamericana. Revista de estudios interculturales, Universidad Católica de Colombia-Fondazione I.S.L.A per gli Studi Latinoamericani, Salerno-Bogotá, julio-diciembre de 2013, 18, pp. 65-94. 
de manera debida con las correspondientes funciones de cada uno de ellos en beneficio de sus respectivos pueblos.

Con frecuencia algunos desprecian el valor del enriquecimiento teórico sobre estos temas y los soslayan injustamente al considerarlos poco prácticos, sin tomar en consideración la idea de Albert Einstein, según la cual no hay nada más práctico que una buena teoría. Solamente una comprensión precisa de las funciones de la filosofía para facilitar el análisis de los derechos humanos y la democracia permite detenerse en la valoración del significado del componente científico, ideológico y jurídico en el estudio de la interacción entre ellos.

Del mismo modo, resulta indispensable la adecuada utilización del concepto de humanismo, de las implicaciones teóricas y prácticas del manejo adecuado de las exigencias que este plantea. Se debe tener siempre presente la máxima kantiana referente a tomar al hombre siempre como fin y nunca como medio, en cuanto a la esencia del vínculo entre derechos humanos y democracia. Un obstáculo para la mayor difusión de los estudios sobre los derechos humanos y la democracia en los últimos tiempos ha sido el auge del pragmatismo neoliberal, que ha inducido a abandonar el estudio de las ciencias sociales y las humanidades, como inservibles o poco productivas en cuanto a rentabilidad inmediata. Se trata de soslayar el importante papel que pueden desempeñar las humanidades en la vida democrática, como ha demostrado Marta Nussbaum:

\begin{abstract}
Las democracias cuentan con un gran poder de imaginación y raciocionio, pero también son propensas a las falacias, al chovinismo, a la prisa, a la dejadez, al egocentrismo y a la estrechez de espíritu. La educación orientada principalmente a la obtención de renta en el mercado global magnifica estas fallas y produce semejante grado de codicia obtusa y de docilidad capacitada que pone en riesgo la vida misma de la democracia, además de impedir la creación de una cultura mundial digna. ${ }^{15}$
\end{abstract}

Ella demuestra que el estudio de las humanidades no solo resulta útil a la democracia, sino también a la creatividad tecnológica y empresarial. Con el fin de superar algunos de los obstáculos que se le presentan a la democracia, muchos intelectuales latinoamericanos propugnan el mayor cultivo de la enseñanza de las humanidades, ya que:

15. M. Nussbaum, Sin fines de lucro. Por qué la democracia necesita de las humanidades, Katz, Buenos Aires, 2010, p. 188. 
La época contemporánea exige de nuevo, como antaño, la incidencia transformadora del humanismo. La alienación existente en los dominios económico, político, social y cultural, la cosificación de las relaciones sociales, la deshumanización característica de la realidad cotidiana requieren del humanismo una presencia más efectiva. Solo desde su perspectiva puede organizarse el cúmulo de conocimientos adquiridos por las humanidades y alcanzar la trascendencia necesaria para que ello se revierta en la cotidianidad moral del individuo e incida en la transformación política de la sociedad, con lo humano como objeto de su intencionalidad teórica y la superación del hombre y su entorno como único fin de actividad. ${ }^{16}$

De igual modo, Guillermo Hoyos reivindicaba la función práctica de la filosofía al sostener:

Por esto quiero formular desde un principio mi tesis: la filosofía no solo sirve de fundamento al movimiento revolucionario que establece jurídica y políticamente los derechos humanos, de suerte que se diga que allí se tradujo la filosofía de los libros a la realidad; en este momento sería verdadero lo que enuncia Hegel: que la revolución obtiene de la filosofía su primer impulso. Pero precisamente en cuanto la filosofía, por su naturaleza de reflexión sobre la historicidad del hombre, no se puede agotar en ninguna de sus articulaciones históricas, es ella misma arma de lucha y de crítica frente a cualquier positivización de la idea del hombre. ${ }^{17}$

De manera que la filosofía en general, y en particular la filosofía política, debe proporcionar peligrosas herramientas de desarticulación de los regímenes totalitarios. De ahí que Herman Göring dijera que cuando escuchaba la palabra cultura, sacaba la pistola. La filosofía política, al igual que otras disciplinas jurídicas, sociológicas, antropológicas, etcétera, ha desempeñado un protagónico papel en la crítica a las dictaduras y a la violación de los derechos humanos. Por ello, muchos de sus cultivadores, en el mejor de los casos, han sido censurados, cuando no desaparecidos.

Resulta paradójico que la democracia y, especialmente, los derechos humanos hayan alcanzado en el capitalismo un punto crucial para su desarrollo -pues no cabe duda de que aunque ambas entidades existían desde la Antigüedad, es a partir de la modernidad

16. O. Mejía Quintana, El humanismo crítico latinoamericano, M\&T, Bogotá, 1993, p. 79.

17. G. Hoyos, "Los derechos humanos como problemas filosóficos," en I Congreso Internacional de Filosofía Latinoamericana, Ponencias, Universidad Santo Tomás, Bogotá, Junio 15-21 de 1980, p. 308. 
cuando adquieren una conformación extraordinaria-, y sin embargo, precisamente es en esta sociedad donde se muestran no solo sus posibilidades de perfeccionamiento, sino sobre todo los obstáculos para su plena realización. Tales limitaciones motivarían las tempranas críticas de socialistas utópicos, anarquistas y comunistas, en especial los diversos intentos por lograr un tipo de sociedad más justa y humana, como los que se produjeron en América, la mayoría de ellos articulados a la intención de completar las conquistas de las luchas independentistas.

La Comuna de París, así como los procesos revolucionarios y ensayos socialistas que se han producido a partir de la Revolución de Octubre en Rusia, se han inspirado en lograr superiores formas de sociedades democráticas, pero otra pregunta es si siempre lo han logrado. Incluso, hasta ideólogos del liberalismo han criticado las profundas injusticias que afloraban en la sociedad moderna y que debían ser enmendadas. El hecho de que algunos identificados con el liberalismo -como se puede apreciar en José Martí, Enrique José Varona, José Ingenieros, Pedro Henríquez Ureña, Carlos Vaz Ferreira, José Enrique Rodó, etcétera-hayan coincidido finalmente con muchas de las críticas de los socialistas a las injusticias sociales y la carencia de derechos plenos de las clases populares demuestra cierto nexo de continuidad entre ambas ideologías, en su coincidencia de distanciamientos en relación con el conservadurismo y los más aristocráticos sectores oligárquicos.

Existen elementos suficientes que evidencian que es la propia naturaleza de las enajenantes relaciones de producción capitalistas las que portan en su seno intrínsecamente tales contradicciones con la justicia social, la democracia y los derechos humanos. Este hecho debe conducir a la conclusión de que mientras exista tal tipo de enajenante sociedad, las violaciones de los derechos humanos y las insuficiencias de la democracia se mantendrán. ${ }^{18}$ Tal vez se podría llegar a la antinómica conclusión según la cual, si bien la sociedad burguesa propició el auge de las ideas y prácticas democráticas modernas, y de las conquistas de los derechos humanos, las enajenantes relaciones de producción, distribución y consumo de la riqueza social, así como las instituciones del aparato estatal benefactor, fundamentalmente de los intereses de la clase dominante, constituyen un serio obstáculo a la larga para su plena realización. Esa ha sido la pretensión del socialismo en sus diversas modalidades, y algunos de sus ensayos han logrado al respecto mayores o menores éxitos, así como rotundos fracasos que en modo alguno validan la hipótesis de que no se puedan alcanzar sociedades más democráticas que las de actual existencia o que nunca se alcancen conquistas superiores de realización de los derechos humanos.

18. Véase M. Burgos Matamoros, "Apuntes críticos a la razón liberal dominante de los derechos humanos" en Y. León (comp.), La paloma: utopía y liberación, Goethe Institut-Filosofia.cu-Editorial Caminos, México, 2014, pp. 131-154. 
Solo una perspectiva misantrópica o nihilista de la historia puede desconocer los avances democráticos y en cuanto a los derechos humanos logrados en los últimos milenios de la civilización, en especial desde mediados del último hasta nuestros días. El humanismo latente en lo mejor del pensamiento filosófico latinoamericano se ha caracterizado por todo lo contrario, es decir, por una profunda confianza en la perfectibilidad de la condición humana, frente a las concepciones que enaltecen una presunta naturaleza o una metafísica esencia humana. Uno de los factores principales que obstaculiza la realización de la vida democrática y la práctica efectiva de los derechos humanos es reducirlos a una mirada de exclusividad política, en lugar de valorar la extraordinaria dimensión social de su análisis y las pretensiones para conquistarlos. Este hecho es lo que algunos autores, con razón, han denominado democracia mínima, ${ }^{19}$ con la cual los sectores populares deben conformarse hasta que aparezcan en el horizonte posibilidades mejores, en tanto los oligárquicos disfrutan a sus anchas.

Ya desde el proceso independentista latinoamericano se puso de manifiesto el serio obstáculo que se les presentaba a la democracia y los derechos humanos si estos eran considerados solo como necesarias conquistas políticas. Al respecto, Arturo Andrés Roig expresaba:

Las manifestaciones de una democracia no controlada por los "hombres de luces" fue constantemente motivo de alarma y condicionó la recepción del mensaje bolivariano. Esas formas le dieron y anticiparon algo que nos parece ser lo más importante de nuestro proceso: la ampliación de aquellos derechos que en manos de la plebe corrían siempre el riesgo de adoptar formas "exageradas". ${ }^{20}$

Algo similar había sucedido durante la Revolución francesa, cuando la burguesía iba codo a codo con los sectores populares del llamado Tercer Estado, pero una vez alcanzada de victoria sobre la monarquía y el viejo régimen feudal, entonces produce un distanciamiento y luego un enfrentamiento por los "excesos" del pueblo en cuanto a demandar conquistas sociales.

Bolívar, Artigas, Hidalgo, Morelos, Martí y los demás próceres de la independencia de los pueblos latinoamericanos no limitaban su lucha a la esfera política, sino que aspiraban a trascender en cuanto a conquistas de mayores logros en relación con la justicia

19. Véase O. Astorga, “Gramsci y el problema de la democracia”, en F. Álvarez, H. Calello, C. Kohn, O. Astorga, E. Quintana, S. Neuhaus et al., Gramsci en América Latina. Del silencio al olvido, Fondo Editorial Tropykos, Caracas, 1991, p. 51.

20. A. A. Roig, Ética del poder y la moralidad de la protesta. La moral latinoamericana de la emergencia, Corporación Editora Nacional, Quito, 2002, p. 104. 
social. ${ }^{21}$ Del mismo modo, todas las batallas posteriores que estos han emprendido hasta la actualidad están orgánicamente articuladas a tales aspiraciones. De ahí que cualquier análisis que pretenda alcanzar una adecuada comprensión de dicha problemática tenga el riego de errar en un enfoque reduccionista epistemológico si limita el análisis solo al ámbito político. Al respecto, Atilio Borón, con acierto, plantea:

En síntesis: los problemas objetivos y concretos que acosan la marcha de la democracia en América Latina trascienden holgadamente aquellos referidos a la exclusiva mecánica del régimen político. Permanecer encerrados en una concepción "politicista” de la democracia obnubila nuestra visión y nos instala en un universo ficcional que no guarda correspondencia con los procesos reales y concretos que conmueven a nuestras sociedades. ${ }^{22}$

Por supuesto que esto no debe significar el menosprecio del importante papel de las luchas políticas, pues estas constituyen el elemento catalizador principal para que los sectores populares logren mejores condiciones de vida. Pero de ahí a limitar las luchas sociales a conquistas políticas va un largo trecho. Ciertamente, "Quien no tiene derechos políticos en realidad no tiene cómo reclamar y defender y menos gozar de derechos civiles. La libertad y seguridad individual son algo que solo la libertad y participación políticas pueden hacer parcialmente posibles. El movimiento obrero se movilizó para conquistar estos derechos en el ámbito de los Estados-nación en construcción. Lo que hay de democracia en estos Estados representativos generalmente es la impronta de la historia de la plebe trabajadora”. ${ }^{23}$ Por lo tanto, la lucha política es esencial no solo como posibilidad para favorecer a los trabajadores exclusivamente, sino para muchos otros sectores sociales que se benefician con sus conquistas, y cualquier obstáculo que se le interponga repercutirá de manera negativa en las condiciones de vida de todos ellos.

Es cierto que tanto los logros como los fracasos de la vida democrática estimulan la seguridad en amplios sectores sociales, en particular en países latinoamericanos sometidos a largas dictaduras, pero también, las limitaciones de su alcance favorecen el escepticismo en otra parte de la población. Al respecto, Fernando Martínez Heredia plantea:

21. Véase P. Guadarrama, "Pensamiento independentista latinoamericano, derechos humanos y justicia social", en Criterio Jurídico Garantista, Revista de la Facultad de Derecho, Universidad Autónoma de Colombia, año 2, 2, enero-junio de 2010, pp. 178-205. http://www.fuac.edu.co/ recursos_web/ documentos/derecho/revista_criterio/revista_criterio_no2.pdf 22. A. Borón, "La sociedad civil después del diluvio neoliberal", en E. Sader, P. Gentili (compiladores), La trama del neoliberalismo. Mercados, crisis y exclusión social, Editorial Ciencias Sociales, La Habana, 2003, p. 46.

23. L. Tapia, "La conquista de la democracia”, en A. García, R. Gutiérrez, R. Prada, L. Tapia, El fantasma insomne. Pensamiento del presente desde el Manifiesto Comunista, Muela del Diablo Editores, La Paz, 1999, p. 188. 
Anotaré solamente que el valor "democracia”, en su realidad y en su mito, es muy compartido por millones de personas activas que estiman que al menos garantiza un sistema con derechos cívicos codificados. Otros millones le conceden intangibilidad al régimen vigente, remitiéndolo a un campo inerte, en el que no participan. Gran parte de los componentes de ambos grupos no creen que esos regímenes resolverán los problemas básicos de sus países. ${ }^{24}$

En verdad independientemente de las limitaciones que puedan observarse en cualquier país que ensaya formas democráticas de vida política, por reducidas que estas puedan ser, el balance final siempre resultará favorable a la mayor parte de la población, que es la que en definitiva más las necesita, pues es sabido que las minorías oligárquicas no son propensas a promoverlas ni tampoco a favorecer la garantía de los derechos humanos. La historia latinoamericana está plagada de ejemplos que evidencian la marcada tendencia de estas últimas a identificarse mejor con los regímenes dictatoriales que con gobiernos propiamente democráticos.

Un frecuente error de algunos miembros de las izquierdas latinoamericanas ha consistido en minimizar las posibilidades de la democracia representativa por considerarla simplemente como burguesa, formal e incapaz de favorecer de algún modo los intereses de los sectores populares. Sin duda, esto ha constituido un obstáculo durante muchos años y ha frenado múltiples procesos o programas democráticos en varios países de la región. Es conocido cómo algunos partidos comunistas han tenido, en el mejor de los casos, distanciamientos críticos ante gobiernos o líderes de orientación popular. Por fortuna, los procesos de elección de gobiernos de orientación de izquierda en varios países latinoamericanos con el nacimiento del siglo XXI hicieron rectificar la postura de algunos, aunque no de todos los partidos y sectores de izquierda, ante esos gobiernos que han gozado de la mayoría del apoyo del pueblo dadas las medidas y transformaciones sociales emprendidas y ya constatables. Ante tales evidencias no han tenido otra posibilidad que apoyar de un modo u otro a tales ensayos de utopías concretas de proyectos socialistas en diversas modalidades, ante la imposibilidad de realizar utopías abstractas.

Durante mucho tiempo, sobre todo después de la experiencia armada de la Revolución cubana, se identificó como reformista y evolucionista a todo aquel que considerase la lucha electoral como una posible vía de acceso a sociedades más justas, ignorando que Marx y Engels no habían subestimado las potencialidades del parlamentarismo obrero.

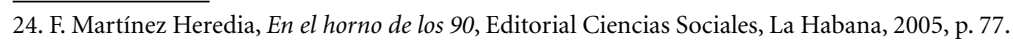


Sin embargo, la vida política, en especial en los inicios del siglo XXI, ha demostrado todo lo contrario. Aprovechando las posibilidades brindadas por la lucha electoral, varios gobiernos de izquierda han triunfado y han podido, con mayor o menor éxito, lograr significativas transformaciones sociales, con lo que han demostrado que la vida democrática, si se canaliza de la manera adecuada, puede contribuir a mejorar de inmediato las condiciones de vida de amplios sectores sociales y favorecer la conquista de algunos derechos sociales que beneficien a toda la población.

Por ello en ocasiones se considera, no sin faltar alguna razón, que uno de los principales obstáculos para los avances democráticos en América Latina han sido los prejuicios de ciertos sectores de la izquierda, en especial los más extremistas, en relación con las posibilidades que pueden ofrecer la lucha electoral y la democracia representativa. De ahí que algunos consideren que es más fácil unir a los sectores de la derecha que a los de la izquierda, y muchas veces cuando se logra, esta misma se encarga de destruir la unidad. Sin embargo, la historia es testaruda y obligó a la izquierda tradicional a reconsiderar muchas de sus concepciones y actitudes ante la democracia tradicional, ${ }^{25}$ e incluso a entrar en sus reglas de juego para intentar asumir el poder, ${ }^{26}$ como finalmente logró acceder en algunos países latinoamericanos en este tránsito de milenios.

La experiencia de los procesos democráticos ha obligado a concepciones algo más abiertas de la izquierda, tanto tradicional como a las nuevas izquierdas emergentes, a fin de tratar de superar los obstáculos que presenta la tradicional democracia formal, así como aprovechar sus potencialidades. De ahí que Marta Harnecker sostenga:

Pero para que esta tarea pueda ser llevada con éxito se requiere de una nueva cultura de izquierda. Una cultura pluralista y tolerante, que ponga por encima lo que une y deje en segundo plano lo que divide; que promueva la unidad en torno a valores como la solidaridad, el humanismo, el respeto a las diferencias, la defensa de la naturaleza, rechazando el afán de lucro y las leyes del mercado como principios rectores de la actividad humana. Una izquierda que comienza a darse cuenta de que la radicalidad no está en levantar las consignas más radicales ni en realizar las acciones más radicales -que solo unos pocos siguen porque asustan a la mayoría-, sino en ser capaces de crear espacios de encuentro y de lucha para amplios

25. Véase M. Barrera: La idea de izquierda en Chile de fines del siglo XX, Taller de Estudios Políticos, Santiago, 1993, p. 6. 26. Véase P. Guadarrama, “Las nuevas izquierdas en América Latina y la cuestión del poder”, en Marx Vive: izquierda y socialismo en América Latina, Universidad Nacional de Colombia, Bogotá, 31 de octubre - 1 de noviembre de 2008, pp. 97-120. 
sectores; porque constatar que somos muchos los que estamos en la misma lucha es lo que nos hace fuertes, es lo que nos radicaliza. Una izquierda que entiende que hay que ganar hegemonía, es decir, que hay que convencer en lugar de imponer. ${ }^{27}$

Es en ese plano en el que se les plantean grandes desafíos a las nuevas izquierdas en cuanto a la conciliación no solo con formas de pluralismo político, sino también de articulación con el mercado, ${ }^{28}$ tomando en consideración que todos los tipos de totalitarismos estatales, y en especial en relación con el mercado, han fracasado.

Por supuesto que resulta negativo también hiperbolizar este tipo de democracia e ignorar que existen otras formas efectivas de democracia directa, como la participativa en diferentes instancias y niveles societales, y aunque no siempre han ofrecido ejemplos dignos de seguir, sobre todo cuando se han articulado a determinadas formas de populismo y voluntarismo, no se deben eliminar de forma nihilista del repertorio de posibilidades que tienen ante sí los pueblos latinoamericanos para ensayar nuevas formas de democracia. Tales nuevas formas de democracia obligan a pensar en otras vías que no son los partidos políticos tradicionales de derecha o de izquierda, sino a través de modos renovados de organización social y política que posibiliten un verdadero pluralismo y no el de dos ancestrales partidos que se alternen en el Gobierno, aunque los dos siempre se mantengan en el mismo poder. ${ }^{29}$

Son varios los cultivadores de la filosofía política de América Latina que han elaborado propuestas alternativas de superación de los obstáculos que se han presentado a la realización de formas superiores de democracia como Guillermo Hoyos, quien expresa:

Frente al agotamiento político de la democracia meramente representativa y a la desmovilización política provocada por la democracia meramente directa, se sugiere profundizar en el sentido de la democracia participativa: que no es una nueva forma de democracia directa, sino una nueva forma de concebir la política, como política deliberativa y democracia radical: desde la raíz, es decir, desde la "soberanía popular". ${ }^{0}$

27. M. Harnecker, América Latina y el socialismo del siglo XXI inventando para no errar, Secretaría de la Paz de la Presidencia de la República de Guatemala, Guatemala, 2010, p. 127.

28. I. Wallerstein, A. Caillé, Repensar la izquierda: Nuevos caminos para la izquierda, Textos, Bogotá, 2000, p. 43.

29. E. Duharte, "Los sistemas políticos: algunas reflexiones conceptuales", en Teoría y procesos políticos contemporáneos, Editorial Félix Varela, La Habana, 2006, tomo I, p. 122.

30. G. Hoyos, Convergencia entre ética y política, Siglo del Hombre Editores, Bogotá, 1998, p. 13. 
Como puede apreciarse, en este caso se apuesta más por el enriquecimiento de la sociedad civil como una vía de perfeccionamiento de la democracia participativa, que no excluye, sino que complementa, otras vías tradicionales de ejecución del poder democrático. Sin embargo, confiar demasiado en las potencialidades de la sociedad civil puede también resultar contraproducente, pues cualquier lucha que subestime las vías políticas de perfeccionamiento de la democracia y de realización de los derechos humanos puede convertirse en un bumerán que afecte el protagonismo de viejos y nuevos sujetos sociales. Según Norbert Lechner: "En América Latina el recurso a la sociedad civil critica la fragilidad $y$, muchas veces, simple formalidad del régimen democrático. Es conocida la oposición entre democracia formal y democracia sustantiva que por tantos años caracterizó el debate político de la región. La democracia sustantiva tenía como referente al pueblo, pero más como categoría social que política". ${ }^{31}$ Esto puede significar que el añorado protagonismo de la sociedad civil en una democracia sustantiva no debe subestimar las posibilidades que siempre ofrecerá la democracia en sus instancias políticas, por formal que esta se presente. De manera que parece que la vía más adecuada para el logro de formas superiores de democracia implica articular debidamente la formal y la sustantiva. ${ }^{32}$

Nadie duda de que el protagonismo de la sociedad civil se ha enriquecido en todo el mundo, en particular desde la posguerra y el declive de los totalitarismos hasta nuestros días. Aunque estos últimos no desaparecieron del todo, sin duda fueron debilitándose, al menos en la mayor parte de Europa. En el caso de América Latina, con excepción de la larga noche de las dictaduras fascistoides, no solo del Cono Sur, este hecho posibilitó que surgieran nuevas instituciones como las organizaciones no gubernamentales y los movimientos sociales, que aparecerían simultáneamente con la crisis de los partidos políticos, tanto de derecha como de izquierda. Estas entidades constituyen una evidente manifestación de que la democracia reverdece, en especial en la defensa de los derechos humanos de viejos y nuevos sujetos sociales; pero:

Es cierto que se reconoce que a comienzos de la década de los noventa la totalidad de los países han recuperado la democracia, algunos después de cruentas dictaduras, y se han reconquistado espacios importantes de libertad, de expresión y de organización social. Sin embargo, conjuntamente se señala que hay pérdida de

31. N. Lechner, "La problemática (invocación) de la sociedad civil", en P. S. Rodríguez, Las incertidumbres de la democracia, Ediciones Foro Nacional por Colombia, Bogotá, 1995, p. 34.

32. J. Alonso, "Democracia y ciencias sociales", en M. Hernández, J. Lameiras, Las ciencias sociales y humanas en México. Síntesis y perspectiva de fin de siglo, Editores El Colegio de Michoacán, México, 2000, pp. 168-169. 
confianza en la democracia tradicional de los partidos políticos, que se vive en un sistema formalmente democrático pero profundamente antidemocrático en sus estructuras, en su autoridad y en sus relaciones. ${ }^{33}$

Por tanto, es válido arribar a la conclusión de que el fortalecimiento de la sociedad civil de forma íntegra, sin ignorar determinadas concepciones y prácticas democráticas, como las de los pueblos originarios de este continente, constituye una de las vías principales para la renovación y reformulación de la vida democrática. La postura mimética pretende hiperbolizar la cuestionable democracia esclavista ateniense o las diversas formas sectarias, clientelistas y elitistas de democracia en el mundo occidental. A la vez se desconocen o subestiman las potencialidades renovadoras de otras formas de democracia, como las de los pueblos ancestrales, lo mismo de América que de otras latitudes. Miró Quesada, al respecto plantea:

Es fundamental rescatar esta forma democrática andina, respetando su funcionamiento, producto de la tradición y la costumbre, que es perfectamente compatible con la democracia moderna. Esta es una forma de democracia directa, resultado de una organización peculiar: la del ayllu, cuyo fundamento social y económico se sustenta en la minka o trabajo solidario y, como sabemos, la democracia es también solidaridad, además de igualdad y libertad. ${ }^{34}$

Con una intención similar, pero evidenciando una vía imprescindible para su realización Rodrigo Uprimny plantea:
Paradójicamente, solo reconociendo normas para toda la humanidad se puede pensar en una verdadera tolerancia a la diversidad cultural. Pero solo aceptan- do la diversidad cultural podremos realmente reconocer la igualdad de todos los seres humanos y construir una universalidad de los derechos humanos, que no sea sinónimo de una uniformización empobrecedora de las culturas, sino de un enriquecimiento dentro de la diversidad. Y en eso consiste lo que llamo la "uni-diver-salidad" de los derechos humanos, que es a mi juicio una forma posible

33. A. Magendzo, "El autoritarismo está presente y a veces con fuerza. Introducción. La educación en derechos humanos en América Latina: Una mirada de fin de siglo". http://www.derechoshumanos.unlp.edu.ar/assets/files/documentos/la-educacion-en-derechos-humanos-en-america-latina-una-mirada-de-fin-de-siglo-abraham-magendzo.pdf 34. F. Miró Quesada, Defensa de la democracia contra la dictadura, Editorial San Marcos, San Marcos, 2001, p. 65. 
para defender la universalidad de los derechos humanos conservando la riqueza y diversidad de las distintas opciones culturales y personales. ${ }^{35}$

Por esa razón, no todo es color de rosa en cuanto al incremento del protagonismo de la sociedad civil que, como es sabido, desempeñó un significativo papel en el desmonte del socialismo soviético y de Europa Oriental. Precisamente en el momento crucial cuando se producía aquel derrumbe que dejaría sin orientación precisa no solo a admiradores de aquellos ensayos, sino también a quienes con distanciamiento crítico tampoco comulgaban con la alternativa capitalista, intentaban encontrar desde la filosofía política latinoamericana alguna propuesta de alternativa. En verdad, "El límite de la democracia es ensanchar la concepción política de la misma en la dirección de la democracia económica y de la democracia social. El límite de este Estado democrático latinoamericano es superarse a sí mismo, dando lugar a la realización del proyecto de una sociedad alternativa". ${ }^{36}$

El auge de la sociedad civil se ha producido fundamentalmente en las últimas décadas tras el derrumbe del "socialismo real" y el auge del, este sí, "capitalismo real", que en su forma más despiadada de neoliberalismo se ha impuesto con más éxito ideológico que económico, como lo han demostrado las crisis financieras que estallaron en el 2008. González Casanova advierte de los posibles peligros que acechan tras el auge democrático y los significativos triunfos de gobiernos populares en esta región, los cuales han inclinado el péndulo de la historia en distinto grado hacia la izquierda: "Tras las 'fronteras' de la tiranía neoliberal formalmente constitucional y 'democrática' se halla la tiranía neoliberal de facto, golpista. Frente a ambas se encuentran los límites del conformismo popular: su 'capacidad de tolerancia' ante un empobrecimiento sin alternativa y su 'capacidad de tolerancia' ante una opresión abiertamente represiva".37

No debe pasarse por alto que el principal obstáculo que se le plantea a la defensa de los derechos humanos y la democracia radica en que algunos de sus principales ideólogos, como Von Hayek y Friedmann, no disfrazaron su hostilidad ante ellos ni tampoco sus simpatías por la dictadura de Pinochet, a partir del criterio de que éxito empresarial y democracia no son muy buenos amigos. ${ }^{38}$

35. R. Uprimny, "La universalidad de los derechos humanos: Conflictos entre derechos, conceptos de democracia e interpretación jurídica”, en Pensamiento jurídico. Revista de Teoría del Derecho y Análisis Jurídico, Universidad Nacional de Colombia, Bogotá, 9, 1998, pp. 109-110.

36. V. M. Fiorino, "Poder y participación: Los protagonistas de la democracia en América Latina”, en F. Álvarez, H. Calello, C. Kohn, V. Martin, E. Safar, Democracia y violencia política. Ensayos sobre el ejercicio del poder en América Latina, Fondo Editorial de Humanidades y Educación - Universidad Central de Venezuela, Caracas, 1990, pp. 49-50.

37. P. González Casanova, "Prólogo. La trama del neoliberalismo: una introducción”, en E. Sader, P. Gentili (comp.), La trama del neoliberalismo. Mercados, crisis y exclusión social, Editorial Ciencias Sociales, La Habana, 2003, pp. 13-14. 38. J. Child, Fin del Estado. Desestabilización política y caos constitucional, Grijalbo, Bogotá, 1994, pp. 253-254. 
Algunos, Hugo Zemmelman, se han percatado de que con el auge del neoliberalismo, en tiempos de globalización de presunción posmoderna, ${ }^{39}$ se observa un incremento de la democracia política formal y en sentido inverso un decrecimiento de la social: "Existen análisis que llaman la atención sobre el hecho de que en la época de la globalización crece la tendencia de que prevalezca una democracia política encerrada en espacios restringidos y cupulares mientras se lleva a cabo un implacable desmantelamiento de la democracia social". ${ }^{40}$ Esto debe obligar a los luchadores por la democracia y los derechos humanos en el ámbito latinoamericano a prestar mayor atención a la lucha por los derechos sociales, sin descuidar las conquistas alcanzadas en el plano de la democracia política-que siempre resultarán insuficientes para los sectores populares mientras predomine el capitalismo-.

También Blitz Lozada y Marcos Zaavedra plantean:

La democracia neoliberal responde a las necesidades y proyecciones de "clase política"; además, el ejercicio del poder y la "gobernabilidad" le permiten eliminar toda forma de control constitucional. La regulación social de las decisiones políticas ha sido prácticamente anulada. Frente a la herencia de control y regulación, los partidos son más fuertes al exhibir novedosas formas de cinismo y secantes y extrema expresión de autoritarismo. ${ }^{41}$

Un serio obstáculo que se presenta en la actualidad en tiempos de globalización y de auge del neoliberalismo es el debilitamiento de los Estados nacionales y la subordinación por parte de algunos gobiernos a los mandatos de las transnacionales..$^{42} \mathrm{Nadie}$ duda de que el fracaso del experimento socialista soviético y de Europa Oriental ha dado lugar a una gran desconfianza entre los sectores populares en relación con la posibilidad de una sociedad con mayores niveles de justicia social. ${ }^{43}$ Tales desilusiones motivaron el auge de apocalípticas teorías del fin de la historia que parecían enfrentarse ontológicamente a las leyes del universo - del mismo modo que con anterioridad lo habían hecho

39. Véase P. Guadarrama, Cultura y educación en tiempos de globalización posmoderna, Editorial Magisterio, Bogotá, 2006. http://biblioteca.filosofia.cu/php/export.php?format=htm\&id=2181\&view=1.

40. H. Zermeño: La sociedad derrotada, Siglo XXI, México, 1996, p. 152.

41. B. Lozada, M. Saavedra, Democracia, pactos elites. Genealogía de la gobernabilidad en el neoliberalismo, Instituto de Investigaciones de Ciencia Política, La Paz, 1998, p. 156.

42. R. Cervantes, F. Gil, R. Sardoya, “Gobernabilidad, democracia y transnacionalización del poder político", en Colectivo de autores. Teoría sociopolítica. Selección de temas, Editorial Félix Varela, La Habana, 2000, T. II, p. 25.

43. L. Villoro, "La fraternidad base de toda comunidad auténtica", en Colectivo de autores, Coloquio de invierno. Los grandes cambios de nuestro tiempo: la situación internacional, América Latina y México. La situación mundial y la democracia, Consejo Nacional para la Cultura y las Artes - Universidad Nacional Autónoma de México - Fondo de Cultura Económica, México, 1992, p. 92. 
algunas eternizadas concepciones del comunismo-, al tratar de fundamentar la presunta longevidad eterna del capitalismo y de la democracia burguesa.

La dialéctica de la historia ha demostrado retrospectivamente -y siempre es aconsejable aprender de ella para no cometer dos veces el mismo error- que todas las formaciones socioeconómicas, así como sus expresiones jurídico-políticas e instituciones superestructurales, en tanto se han correspondido con determinadas exigencias sociales, se han desarrollado con holgura. Pero en la medida en que demuestran su ineficacia o su carácter obstaculizador de mejoras de determinadas clases sociales, bien oligárquicas o bien populares, han sido sustituidas por diversas vías y formas, entre las que no se excluyen las revoluciones sociales. No parece muy lógico sostener que en el futuro de la humanidad estas últimas desaparecerán del todo y solo prevalecerá un tranquilo desarrollo evolutivo de reformas parciales, que mantendrán en su privilegiada situación a sectores minoritarios de la población, en tanto las mayorías populares deberán contentarse con las migajas del festín de la riqueza producida por ellos mismos.

Preguntarse por los límites y el fin de la democracia neoliberal, y por sus alternativas dentro del sistema con regímenes de facto, con burocracias autoritarias, civiles y militares, aparece como otra forma de acercarse a situaciones en que eventualmente surgirá una alternativa popular y democrática. ${ }^{44}$

El optimismo realista que ha inspirado a los más consecuentes intelectuales de izquierda sobre la caducidad de las formas de democracia tradicional y la posibilidad de la emergencia de nuevos movimientos sociales, nuevas formas de participación ciudadana y, en definitiva, nuevas vías y formas de democracia, da lugar a una permanente creatividad teórica sobre el tema del necesario humanismo práctico que debe caracterizar a las emergentes democracias latinoamericanas de nuevo tipo.

Uno de los grandes desafíos que se plantea en la actualidad a los pueblos latinoamericanos en su afán de hacer cada vez más concreto y aplicable el humanismo práctico en los ensayos de nuevas formas de democracia y de respeto a los derechos humanos consiste en el creciente protagonismo de los sectores populares, no solo en cuanto a las prácticas participativas, sino en cuanto a la argumentación y fundamentación teórica de dicho protagonismo. Esto exige, tanto a los investigadores sociales sobre la democracia y los derechos humanos como a los funcionarios gubernamentales y de la sociedad civil,

44. P. González Casanova, "Prólogo. La trama del neoliberalismo: una introducción”, pp. 13-14. 
tener mucha prudencia en cuanto a la consideración de la validez de los argumentos jurídicos, políticos e incluso filosóficos de líderes de movimientos sociales, a partir de la consideración de que la verdad es siempre un constructo epistémico en el cual colaboran muchos elementos, y no solo los científicos y filósofos (theorike), sino también los cultivadores y promotores de la opinión (doxa) pública, como agentes sociales, líderes, funcionarios, etc.

Sin duda, entre las vías principales para la fundamentación teórica y la promoción del humanismo práctico en las nuevas formas de democracia y la defensa de los actualmente reconocidos y otros por reconocer derechos humanos, se destacan la escuela, las instituciones culturales y los medios masivos de comunicación. Pero paradójicamente, en esas mismas entidades es donde se pueden presentar mayores obstáculos, si tales instituciones son controladas por una elite oligárquica que no permite el desarrollo de nuevas formas de democracia y de defensa de los derechos humanos. ${ }^{45}$ La escuela, las instituciones culturales y los medios de comunicación lo mismo pueden constituir un valioso elemento de cultivo de la dignidad humana y de formación de valores democráticos, así como estimular la defensa de los valores humanos, que ser entidades que fomenten todo lo contrario. Por eso, lo mismo puede ser una valiosa vía que constituir un serio obstáculo. Todo dependerá de la orientación axiológica y, en particular, ideológica que motiven estas entidades.

De todo lo anteriormente planteado se puede concluir que son múltiples tanto las posibilidades como los obstáculos para el desarrollo de la democracia y los derechos humanos. Con escepticismo no totalmente infundado, algunos podrán asumir una postura conservadora y no entrever nuevas altenativas de enriquecimiento del humanismo práctico. Otros, a partir del estudio de la historia universal y, en particular, de las luchas de los pueblos latinoamericanos desde el período colonial hasta la actualidad, pueden tener suficientes argumentos para considerar que el futuro de la democracia y los derechos humanos es prometedor, aun cuando haya que ensayar nuevos tipos de sociedad, que deben partir de los éxitos y fracasos del "socialismo real" y del "capitalismo real".

Las conquistas democráticas y de derechos humanos son el producto de la interacción dialéctica entre las ancestrales luchas de sectores sociales explotados y marginados por su dignificación, conjugada con las elaboraciones teóricas de cultivadores del pen-

45. "En las escuelas hay que promover de manera deliberada la ciudadanía democrática”. P. Castilleja: "Ciudadanía democrática, membresía y equidad”, en Colectivo de autores, Cultura democrática. Comprensiones sobre ciudadanía. Veintitrés expertos internacionales conversan ¿cómo construir ciudadanía y aprender a entenderse?, Cooperativa Editorial Magisterio, Bogotá, 2005, p. 181. 
samiento político. La filosofía política en América Latina ha contribuido al enriquecimiento del arsenal teórico del humanismo práctico universal sobre la democracia y los derechos humanos, que se ha diferenciado de formas de humanismo abstracto que, por lo general, se reducen a filantropía romántica. La preocupación principal del pensamiento humanista latinoamericano se ha centrado en el respeto a la dignidad humana y el reconocimiento de los valores y derechos de hombres y mujeres, minorías étnicas y sectores marginales.

En esta región se ha incrementado de manera notoria la investigación sobre las conquistas democráticas y los derechos humanos desde distintas disciplinas de las ciencias sociales y la filosofía política. Para analizar este tema resulta imprescindible antes esclarecer el marco conceptual en lo referente al Estado, la nación, el humanismo, los derechos de distintas generaciones, las formas y tipos de democracia, las luchas sociales, la filosofía política, etcétera. La definición precisa de cada uno de estos términos facilita la lucha práctica por ellos.

El neoliberalismo, aprovechándose de la crisis del "socialismo real", ha estimulado actitudes pragmáticas y utilitaristas muy distantes del humanismo práctico, con el fin de fundamentar la utopía abstracta del predominio eterno de la sociedad capitalista. Entre las vías principales para promover la democracia y los derechos humanos se encuentra el aprovechamiento, no obstante sus limitaciones por su carácter formal, de la democracia representativa, a la vez que se deben ensayar nuevas formas, como la participativa y la directa. Sin embargo, se deben tomar precauciones dado el carácter clientelista y mercantil prevaleciente en la sociedad capitalista, en la que se presupone que todo se puede vender y comprar, por lo que se promueve la idea de que también el poder democrático puede convertirse en una mercancía más.

La educación, las instituciones culturales y los medios de comunicación pueden ayudar al fortalecimiento de la cultura ciudadana, pero a la vez, si el poder estatal no los controla con eficiencia, pueden convertirse en un peligroso bumerán que atenta contra la propia democracia y los derechos humanos. Entre los obstáculos se encuentra: la mayor parte de los latinoamericanos dedicados al estudio de este tema desde la filosofía política se han percatado de las trampas y subterfugios que están al acecho para hostilizar y desvirtuar cualquier proyecto genuinamente democrático. El mimetismo político ha dado lugar a que se hayan tratado de reproducir de forma dogmática en nuevos contextos viejas formas de promoción de cultura democrática. El humanismo prevaleciente en el pensamiento latinoamericano se caracteriza por una profunda confianza en la perfectibilidad de la condición humana a través de distintas 
vías de la sociedad civil. El humanismo contenido en diversas propuestas socialistas, independientemente de sus fracasados y exitosos ensayos en todo el orbe, ha tratado de superar las enajenantes relaciones de producción capitalistas.

No obstante el reconocimiento de la existencia de innumerables obstáculos para la realización más elaborada y de mayores conquistas democráticas y de los derechos humanos, prevalece una concepción progresiva del desarrollo social, auspiciada por el fortalecimiento de la lucha por tales derechos. La filosofía política desarrollada en Latinoamérica cuenta con un valioso arsenal de ideas propias en relación con las conquistas democráticas y de los derechos humanos. La tarea principal es investigarla a fondo y difundir por el mundo tales conquistas teóricas de incalculable valor práctico. 